\title{
The Design of Flux Barrier for Improvement of Demagnetization Endurance in BLDC Motor
}

\author{
Cheol-Min Kim*, Dong-Yeong Kim*, Gyu-Won Cho* and Gyu-Tak Kim ${ }^{\dagger}$
}

\begin{abstract}
Generally, the motor inside vehicle is exposed to highly ambient temperature and large vibration according to repeatedly starting and stopping for very short time. So, in this paper, the rotor shape design was performed to improve demagnetization endurance by considering the starting current of the Brushless DC (BLDC) Motor through the Finite Element Method(FEM). As a result, the partial irreversible demagnetization was occurred by starting current at the end of Permanent Magnets of the basic model. To solve this problem, the flux barrier design was performed and the flux on the rotor core was limited. Accordingly, demagnetization endurance and operating characteristics were improved.
\end{abstract}

Keywords: BLDC motor, Demagnetization analysis, Barrier design, Improved operating characteristics

\section{Introduction}

BLDC motor drive is relatively simple compared to other permanent magnet type motors. So, the cost of controller could be reduced in the BLDC Motor. That's why BLDC motor is widely used $[1,2]$. However, the motor inside the vehicle has some disadvantage [3]. The temperature of surrounding environment is very high, and the motor is always exposed vibration. Specifically, if the motor was used in the hydraulic control and brake, a repeatedly starting and stopping would be performed during very short time. So, the design stage of the motor has to consider the partial demagnetization of the PMs by high starting current. Generally, the partial demagnetization can be eliminated through changing the thickness or the materials of the PMs, but the rising cost of the manufacturing and the debasement of operating characteristics were generated. Therefore, in this paper, the flux barrier was installed for an improvement of demagnetization endurance and operating characteristics, but the shape of the PMs was not changed. As a result, not only was partial demagnetization solved but also was operating characteristics was improved.

\section{Application Model}

Table 1. shows specifications of the basic model. Fig. 1. shows the shape of the basic model. This paper's motor was used inside the vehicle. Thus, this motor is always exposed to highly ambient temperature and large vibration. So, the motor in the vehicle's interior must be designed to

$\dagger$ Corresponding Author: Dept. of Electrical Engineering, Changwon National University, Korea. (gtkim@changwon.ac.kr)

* Dept. of Electrical Engineering, Changwon National University, Korea (rla7760@paran.com, mangmoolman@naver.com, chogyuwon@ changwon.ac.kr)

Received: April 11, 2014; Accepted: July 4, 2014

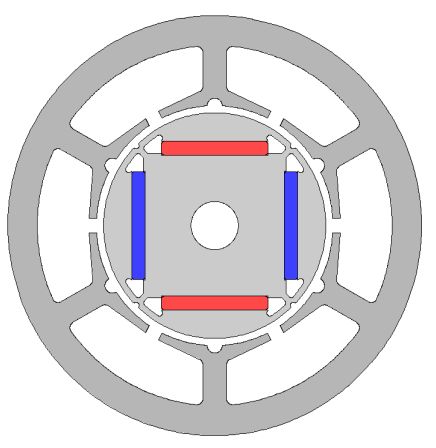

Fig. 1. The shape of the basic model

Table 1. Specification of analyzed model

\begin{tabular}{c|c}
\hline Item & Specification \\
\hline Rated speed $[\mathrm{rpm}]$ & 1.23 .200 \\
\hline Rated torque $[\mathrm{Nm}]$ & 0.55 \\
\hline Rated current $[\mathrm{A}]$ & 13.5 \\
\hline Poles/Slots & $4 / 6$ \\
\hline Air-gap length $[\mathrm{mm}]$ & 1.2 \\
\hline Winding type & Concentrated winding \\
\hline PM material & $50 \mathrm{PN} 1300$ \\
\hline Core material & 41 \\
\hline Stack length $[\mathrm{mm}]$ & 70 \\
\hline Stator diameter $[\mathrm{mm}]$ & $0.15\left(25^{\circ} \mathrm{C}\right)$ \\
\hline Phase Resistance $[\Omega]$ &
\end{tabular}

consider high temperature and vibration $[4,5]$

\section{Demagnetization Analysis of the Basic Model}

In the motor, maximum current was selected as meaningful current such as stating current, short current, controller maximum current. In this paper, $42[\mathrm{~A}]$ as the starting current was selected by using the FEM [6] and Fig. 2. Shows the starting current wave form. 


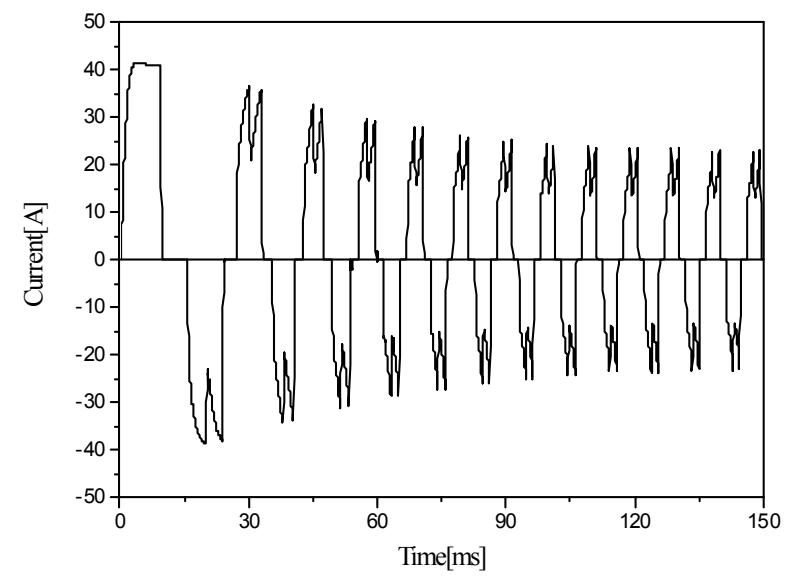

Fig. 2. Calculation of maximum current

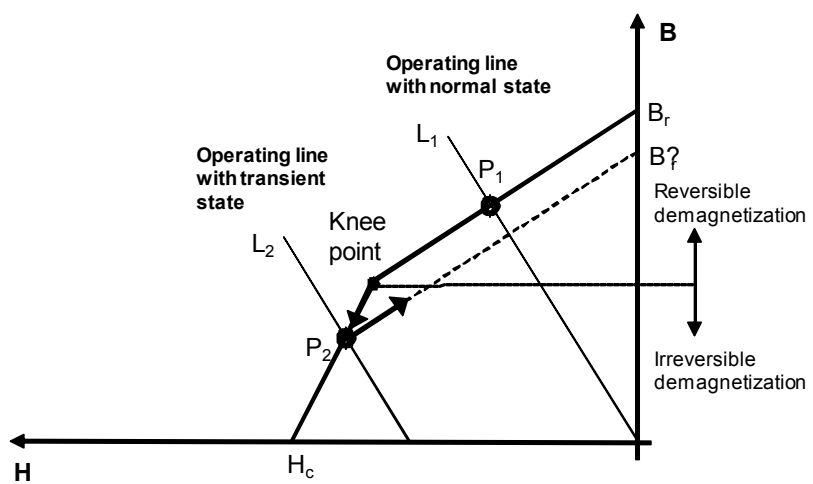

Fig. 3. Calculation of demagnetizing point

The material of the PM was N33SH, and demagnetization endurance was calculated by the FEM in state of starting current. In Fig. 3, the steady-state operating point $(\mathrm{P} 1)$ has higher operating point than the knee point. However, when the starting current is applied, the operating point will move from $\mathrm{P} 1$ to $\mathrm{P} 2$. If the transientstate operating point(P2) is lower than the Knee point, irreversible demagnetization would ne caused.

The valuation of an irreversible magnetization was carried out through the calculation of the minimum flux density of the PMs by FEM analysis. So, if minimum flux density was less than $0.28[\mathrm{~T}]$. An irreversible demagnetization would be generated.

Fig. 4(a) is minimum flux density when the rated current was applied in the basic model. In this case, the magnetic flux density higher than the knee point. As a result, it has sufficient demagnetization endurance. However, such as 4 . (b), when a partially irreversible demagnetization was generated in the basic model in rotor's position at $0^{\circ}$ and $180^{\circ}$ by starting current. In this case, the minimum flux density was $0.028[\mathrm{~T}]$.

Figs. 5 and Fig. 6 show the magnetic vector potential and the magnetic flux density distribution of the basic model in starting current state. According to saturation on the Rib, external magnetic flux was flowed through the end of PMs in starting current. Accordingly, the end of PMs led to an

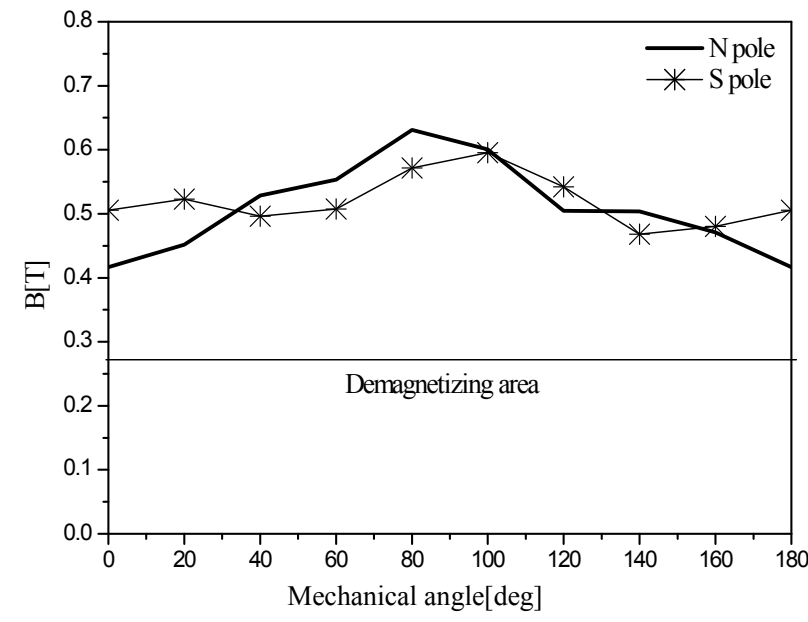

(a) the minimum magnetic flux density at rated current

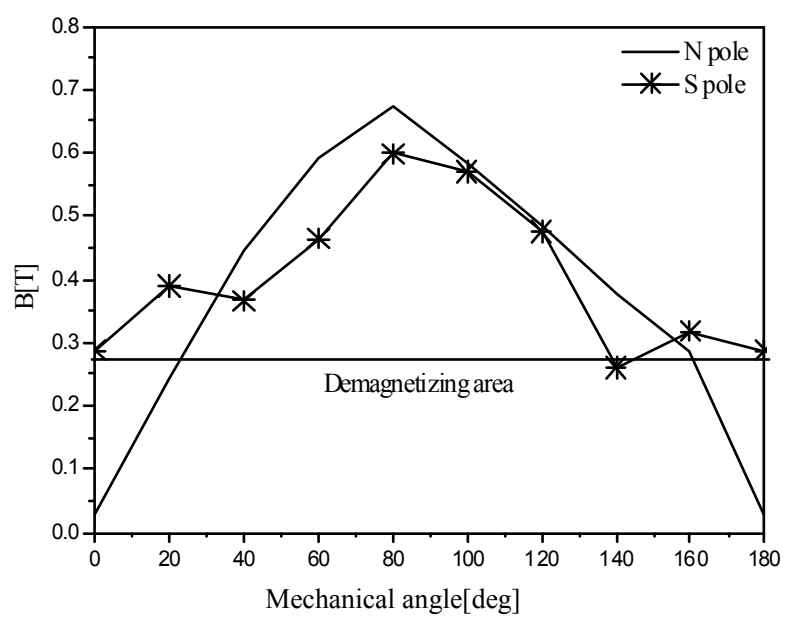

(b) the minimum magnetic flux density at starting current

Fig. 4. Demagnetization analysis of the basic model

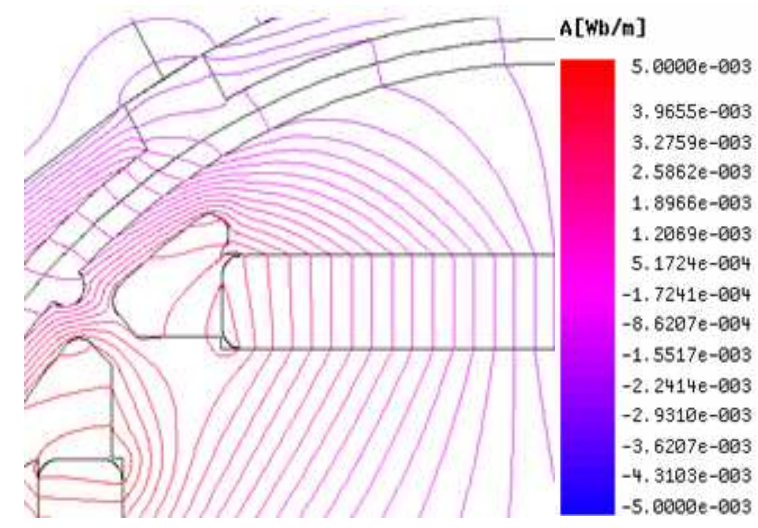

Fig. 5. The magnetic potential of basic $\operatorname{model}\left(\theta=0^{\circ}\right)$

irreversible demagnetization. It knows that the external flux line according to the starting current is not influenced in an overall PM. However, irreversible demagnetization of the PMs occur partially [7]. 


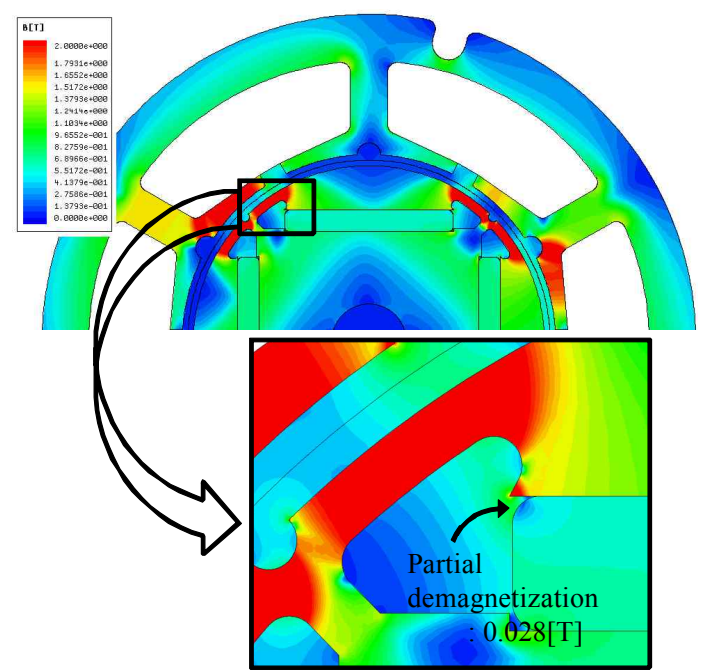

Fig. 6. Magnetic flux density of the basic $\operatorname{model}\left(\theta=0^{\circ}\right)$

\section{The Barrier Design for Improving Demagnetization Endurance}

A partial irreversible demagnetization of the PMs was decreased in Back Electromotive Force(BEMF) and distorted waveform [8]. Therefore, a partial irreversible demagnetization was declined in performance of the motor. Thus, in order to improve demagnetization endurance of the PM, As shown in Fig. 7, the flux barrier was installed on the rotor core to protect the end of the PM and the width of the flux barriers $\left(\mathrm{W}_{\mathrm{b}}\right)$ were set as the design variables.

It is common that the leakage magnetic flux is little when the thickness of the rib is thin. Because the magnetic flux hardly pass through the rib due to the magnetic saturation. However, it causes the mechanical problems in the high speed area. So, the thickness of the rib was selected as appropriate level $1[\mathrm{~mm}]$ by DOE(Design Of Experiment) [3].

\subsection{Operating characteristics according to design variable}

The operating characteristics were compared in accordance with each design variable. In case of the design variables in $13[\mathrm{~mm}]$, Cogging torque is $22[\mathrm{mNm}]$ (peak to peak) and torque ripple is $16[\%]$. Driving characteristics are the most favorable.

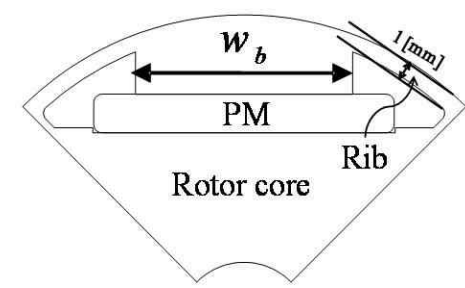

Fig. 7. Flux barrier design parameters

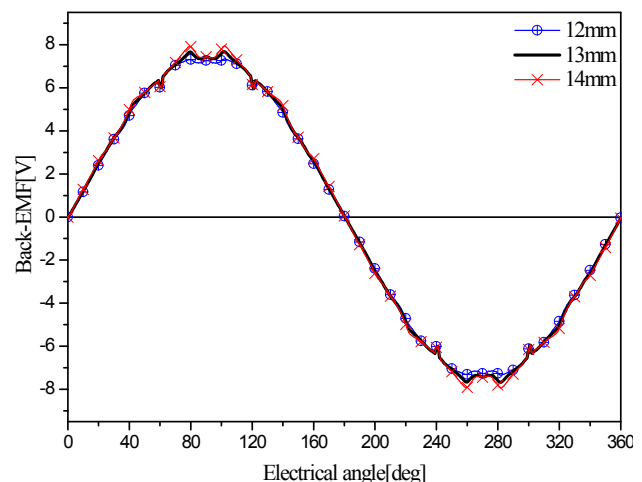

(a) Back-EMF

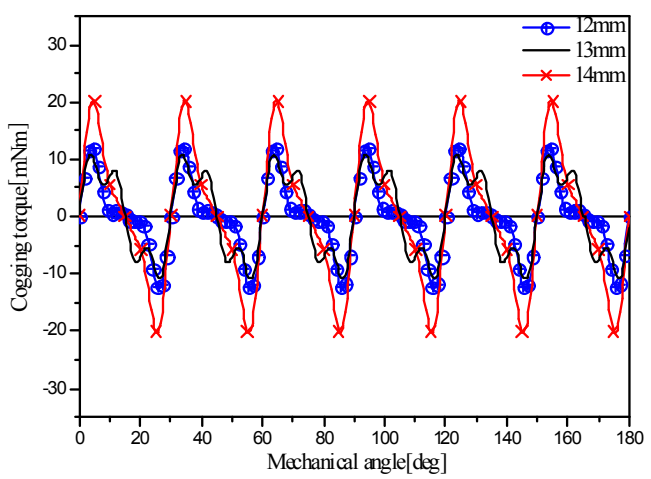

(b) Cogging torque

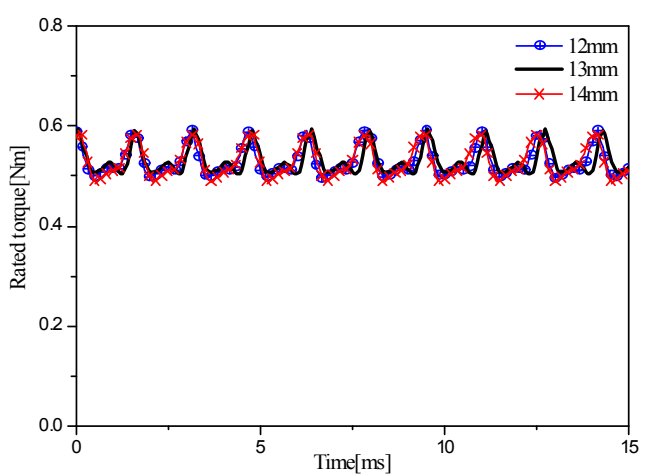

(c) Rated torque

Fig. 8. Comparison of driving characteristics according to design parameters

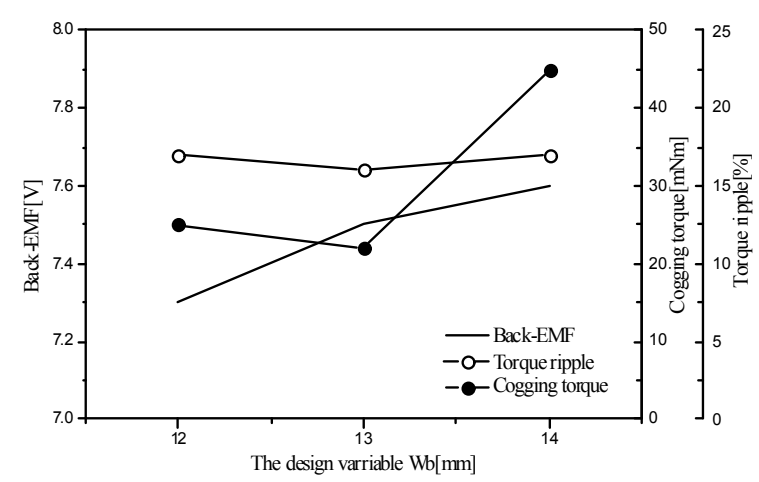

Fig. 9. Operating characteristics according to $\mathrm{Wd}$ 
Table 2. The characteristics according to design variable

\begin{tabular}{c|c|c|c}
\hline $\begin{array}{c}\mathrm{W}_{\mathrm{d}} \\
{[\mathrm{mm}]}\end{array}$ & $\begin{array}{c}\text { Cogging torque } \\
{[\mathrm{mNm}]}\end{array}$ & $\begin{array}{c}\text { Induced voltage } \\
{[\mathrm{V}]}\end{array}$ & $\begin{array}{c}\text { Torque ripple } \\
{[\%]}\end{array}$ \\
\hline 12 & 25 & 7.3 & 17 \\
\hline 13 & 22 & 7.5 & 16 \\
\hline 14 & 45 & 7.6 & 17 \\
\hline
\end{tabular}

\subsection{Demagnetization analysis}

Fig.10. shows the demagnetization analysis according to design variable. In order to avoid the demagnetization of

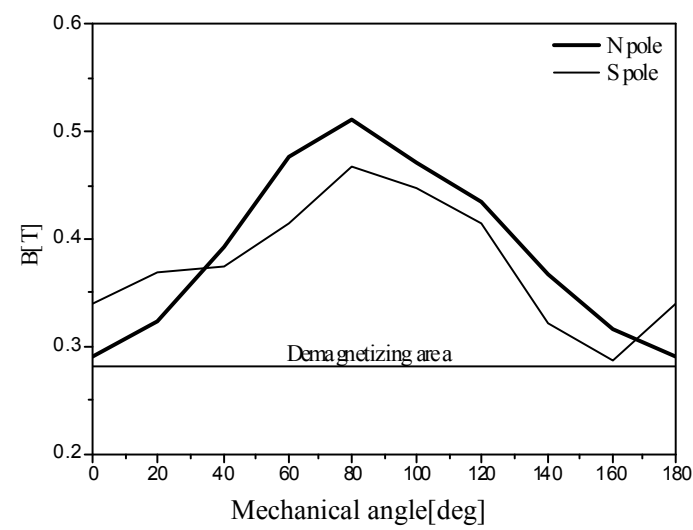

(a) $w_{d}=12[\mathrm{~mm}]$

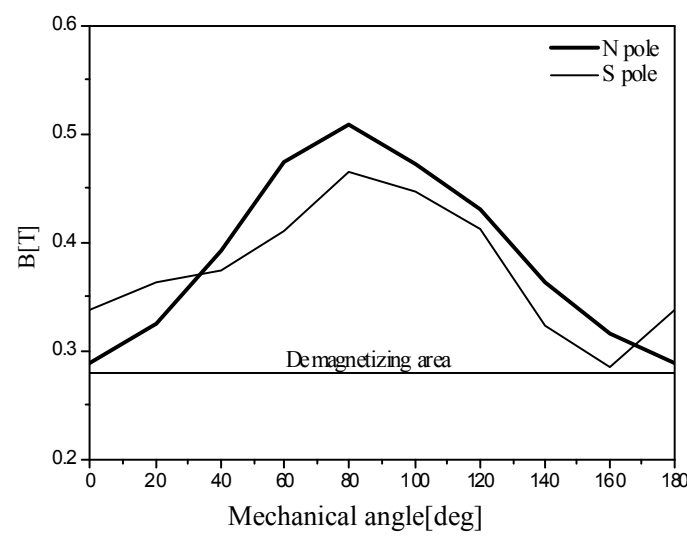

(b) $w_{d}=13[\mathrm{~mm}]$

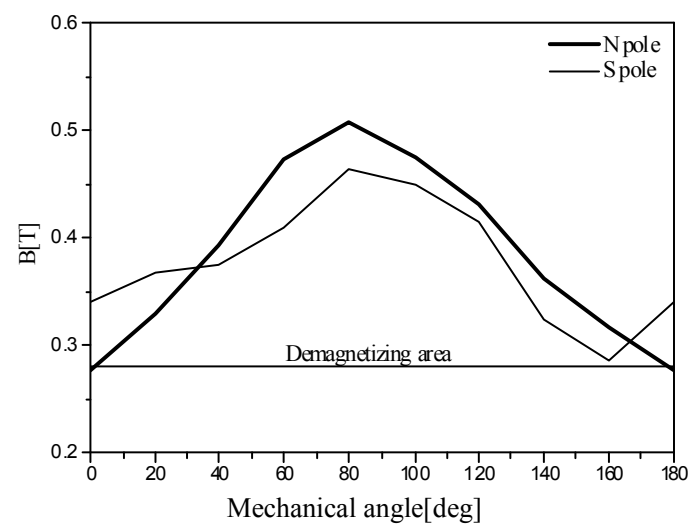

(c) $w_{d}=14[\mathrm{~mm}]$

Fig. 10. Demagnetization analysis of proposed model according to design parameters the PM, the minimum flux density must be larger than Knee point. At the design variable in $14[\mathrm{~mm}]$, the minimum flux density was 0.28 [T]. So, demagnetization endurance was insufficient at the maximum demagnetization angle 0 [deg] and 180 [deg]. At the design variable in $12[\mathrm{~mm}]$ and $13[\mathrm{~mm}]$, the minimum flux density was $0.29[\mathrm{~T}]$. So, an irreversible demagnetization was not caused. And demagnetization endurance was sufficient at the maximum demagnetization angle $0[\mathrm{deg}]$ and 180 [deg].

As a result of the comparison of operating characteristics and demagnetization analysis performed according to design variable. The design variable in $13[\mathrm{~mm}]$ was the one of the best model about the operating characteristics and the demagnetization endurance. So, the design variable Wd was selected for $13[\mathrm{~mm}]$.

\subsection{Demagnetization endurance of the proposed model}

The starting current of the proposed model is applied in the Fig. 8(b), the minimum flux density of each of the rotor's position was higher than Knee point unlike the basic model. The minimum flux density of the proposed model was calculated as $0.29[\mathrm{~T}]$ at overall rotation angle. Figs. 11 and Fig. 12 show the magnetic vector potential

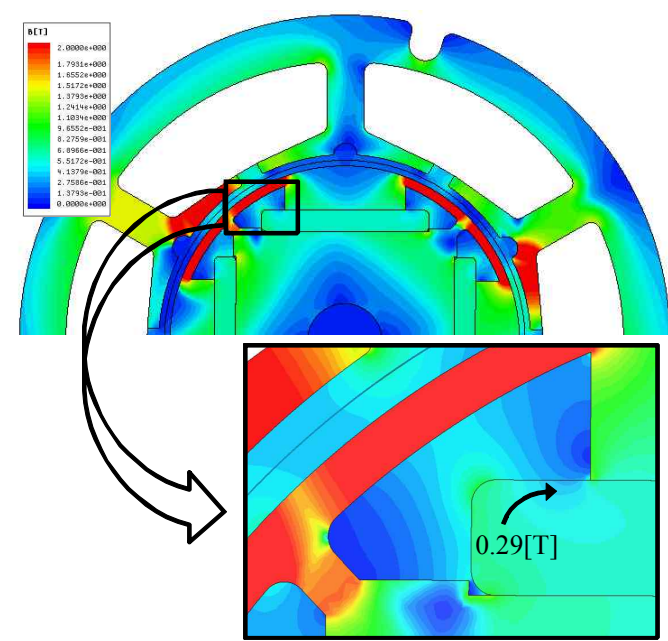

Fig. 11. Magnetic flux density of $\operatorname{proposed} \operatorname{model}\left(\theta=0^{\circ}\right)$

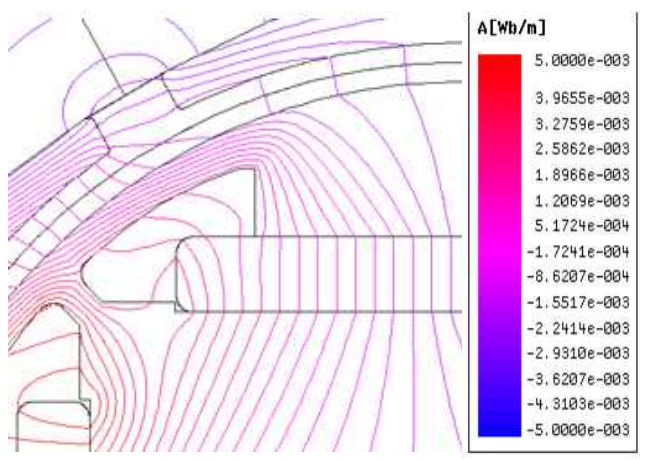

Fig. 12. The magnetic flux line of proposed model 
and the magnetic flux density distribution of the proposed model in starting current state. A partial irreversible demagnetization at the end of the PMs in the basic model was occured. However, installing flux barrier at the end of the PMs in the proposed model. Accordingly, an irreversible demagnetization was not caused at the end of the PMs.

Comparison and analysis were shown about operating characteristics of the proposed model according to installing flux barrier and the basic model at Fig. 13.

\subsection{The driving characteristics of basic model and improved model}

The flux barrier of the proposed model is maintained as the sinusoidal distribution of flux caused by the PM in the air-gap, making the flux density smaller toward the PM of q-axis by d-axis standard [4, 5]. Therefore, in the Fig. 13(c), generated torque through interaction with the PM and slot was reduced up to $83 \%$. However, the supplied current of the BLDC Motor was square waveform. Therefore, a decrease rate of the proposed model's cogging torque was lower in comparison with a decrease rate of the proposed model's torque ripple [9].

Table 2. The comparison of operating characteristics

\begin{tabular}{c|c|c}
\hline Item & Basic model & Proposed model \\
\hline Back EMF [V] & 5.81 & 5.73 \\
\hline Cogging torque[mNm] & 64 & 11 \\
\hline Rated speed [rpm] & \multicolumn{2}{|c}{3,200} \\
\hline Rated torque [Nm] & 0.55 & 0.54 \\
\hline Torque ripple [\%] & 29 & 16 \\
\hline Resistance [ohm] & \multicolumn{2}{|c}{0.26} \\
\hline Iron loss [W] & 11.01 & 11.05 \\
\hline Efficiency [\%] & 63.5 & 63.1 \\
\hline
\end{tabular}

The torque ripple of the proposed model was calculated to $16 \%$ as the Fig. $13(\mathrm{~d})$.

The torque of the proposed model was decreased up to $2 \%$ and the iron loss was increased to $0.4 \%$ and Efficiency was decreased to $0.4 \%$. However, the cogging torque and torque ripple were reduced to individually $83 \%$ and $13 \%$. So, overall operating characteristics were improved. Therefore, operating characteristics and demagnetization endurance were largely improved.

\section{Conclusion}

In this paper, a stating current in demagnetization analysis of the BLDC Motor was calculated by the FEM. and Knee point of N33SH NdFeB PM was selected to $0.28[\mathrm{~T}]$.

According to the FEM, a demagnetization endurance of the basic modal was identified, consequently a partial irreversible demagnetization was caused at rotor's position

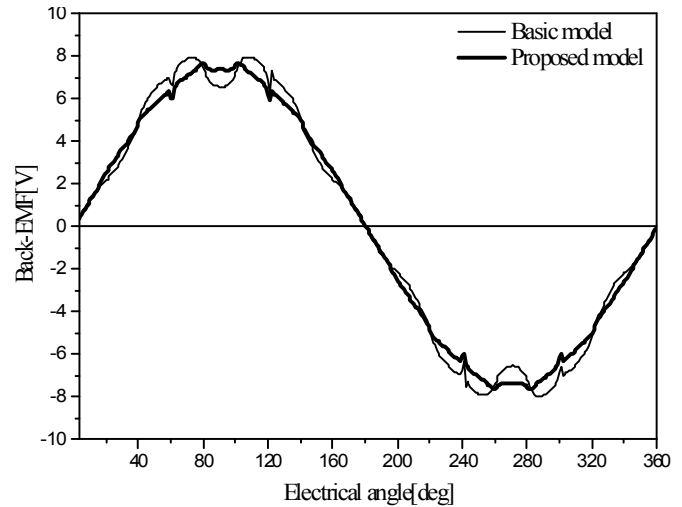

(a) Back-BEMF

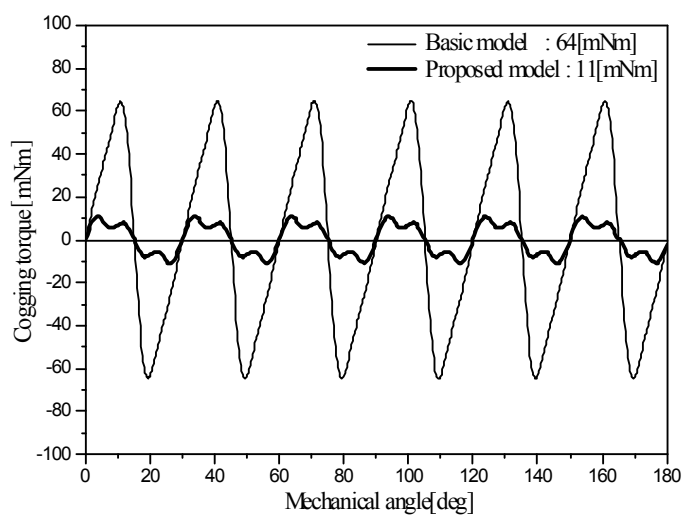

(b) Cogging torque

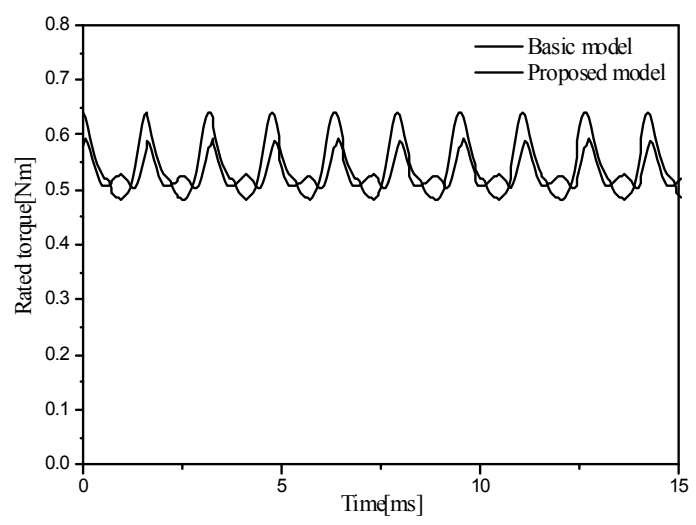

(c) Rated torque

Fig. 13. Driving characteristics of basic model and proposed model

$0[\mathrm{deg}]$ and $180[\mathrm{deg}]$. Therefore, in this paper, the proposed method was protected by installing flux barrier at the end of the PMs. As a result, demagnetization endurance was largely increased.

Also, overall operating characteristics were improved. In addition, demagnetization endurance was too largely improved, and an irreversible demagnetization did not occur. Therefore, it shows that the operating performance of the proposed model was sustained in the extreme operating condition. 


\section{References}

[1] Hong-Seok Ko, and Kwang-Joon Kim, "Characterization of Noise and Vibration Source in Interior Permanent-Magnet Brushless DC motors", IEEE Trans. on Magn., vol. 40, no. 6, pp. 3482-3489, 2004.

[2] Thomas M. Johns, Wen L. Soong, "Pulsating Torque Minimization Techniques for Permanent Magnet AC Motor Drives", IEEE Trans on Industrial Electronics, vol. 43, pp. 321-330,April 1996.

[3] Kwak, J., Min, S. and Hong, J. P., 2010, “Optimal Stator Design of Interior Permanent Magnet Motor to Reduce Torque Ripple Using Level Set Method", IEEE Trans. Magn., vol. 46, no. 6, pp. 2108-2111.

[4] Lee, S. H., Hong, J. P. and Hwang, S. M., 2009, "Optimal Design for Noise Reduction in Interior Permanent-Magnet Motor," IEEE Trans. Ind. Appl., vol. 45, no. 6, pp. 1945 1960.

[5] G. H. Kang, Y. D. Son, G. T. Kim, and J. Hur, "A Novel Cogging Torque Reduction Method for InteriorType Permanent-Magnet Motor", IEEE Trans. on Ind. Appl., vol. 45, no. 1, pp. 161 167, Jan./Feb. 2009.

[6] Christian Kral, Thomas G. Habetler, Ronald G. Harley, Franz Pirker, Gert Pascoli, Helmut Oberguggenberger, Claus-Jürgen M. Fenz, "Rotor Temperature Estimation of Squirrel-Cage Induction Motors by Means of a Combined Scheme of Parameter Estimation and a Thermal Equivalent Model", IEEE Trans. On Industry Applications, vol. 40, no. 4, pp. 1049-1057, 2004

[7] G. H. Kang, J. Hur, H. Nam, J. P. Hong, and G. T. Kim, "Analysis of Irreversible Magnet Demagnetization in Line-Start Motors Based on the FiniteElement Method", IEEE Trans. on Magn., vol. 39, no. 3, pp. 1488-1491, May. 2003.

[8] K. C. Kim, S. B. Lim, D. H. Koo, and J. Lee, "The Shape Design of Permanent Magnet for Permanent Magnet Synchronous Motor Considering Partial Demagnetization", IEEE Trans. on Magn., vol. 42, no. 10, pp. 3485-3487, Oct. 2006.

[9] J. -Y. Lee, S. -H. Lee, G. -H. Lee, J. -P. Hong, and J. Hur, "Determination of arameters considering magnetic nonlinearity in an interior permanent magnet synchronous motor", IEEE Trans. Magn., vol. 402, no. 4, Apr. 2006.

[10] Cheol-Min Kim, Heung-Kyo Shin, Gyu-Tag Kim "The Design of Flux Barrier for Improvement of Demagnetization Endurance in BLDC Motor", ICEMS 2013, PMDC-0677, 2013. 08.

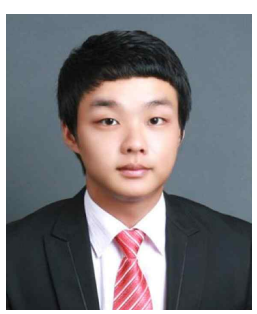

Cheol-Min Kim He received M.S degree in electrical engineering from Changwon National University, Korea. His research interests are electrical machine and FEM analysis.

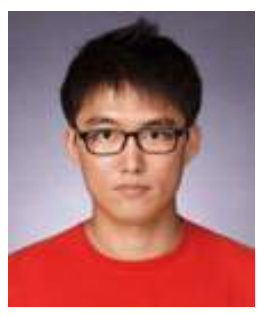

Dong-Yeong Kim He received M.S degree in electrical engineering from Changwon National University, Korea. His research interests are electrical machine and FEM analysis.

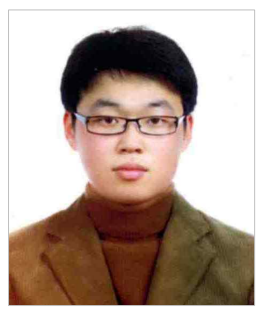

Gyu-Won Cho He received B.S and M.S degree in electrical engineering from Changwon National University, Korea. $\mathrm{He}$ is currently pursuing his $\mathrm{Ph} . \mathrm{D}$. degree at Changwon National University. His research interests are electrical machine and FEM analysis.

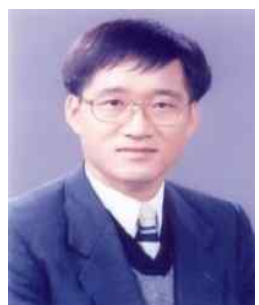

Gyu-Tak Kim He received B.S, M.S and Ph.D degree in electrical engineering from Hanyang University, Korea. $\mathrm{He}$ is presently a Professor of Changwon National University. His research interests are electrical machine and FEM analysis. 